\title{
Flood and Landslide Applications of Near Real-time Satellite Rainfall Products
}

\author{
Yang Hong (1, 2), Robert F. Adler (2), Andrw Negri (2), George J. Huffman (2, 3) \\ ${ }^{1}$ Goddard Earth and Science Technology Center/UMBC \\ ${ }^{2}$ NASA Goddard Space Flight Center, Laboratory for Atmospheres \\ ${ }^{4}$ Science Systems and Applications, Inc \\ Prepared for Journal of Natural Hazards Special Issues: \\ Use of Satellite Remote Sensing for Natural Hazards Analysis
}

\section{Popular Summary:}

Floods and associated landslides are one of the most widespread natural hazards on Earth, responsible for tens of thousands of deaths and billions of dollars in property damage every year. During 1993-2002, over 1000 of the more than 2,900 natural disasters reported were due to floods. These floods and associated landslides claimed over 90,000 lives, affected over 1.4 billion people and cost about $\$ 210$ billion. The impact of these disasters is often felt most acutely in less developed regions. In many countries around the world, satellite-based precipitation estimation may be the best source of rainfall data due to lack of surface observing networks.

Satellite observations can be of essential value in improving our understanding of the occurrence of hazardous events and possibly in lessening their impact on local economies and in reducing injuries, if they can be used to create reliable warning systems in cost-effective ways. This article addressed these opportunities and challenges by describing a combination of satellite-based real-time precipitation estimation with land surface characteristics as input, with empirical and numerical models to map potential of landslides and floods. In this article, a framework to detect floods and landslides related to heavy rain events in near-real-time is proposed. Key components of the framework are: a fine resolution precipitation acquisition system; a comprehensive land surface database; a hydrological modeling component; and landslide and debris flow model components. A key precipitation input dataset for the integrated applications is the NASA TRMM-based multi-satellite precipitation estimates. This dataset provides near real-time precipitation at a spatial-temporal resolution of 3 hours and $0.25^{\circ} \times 0.25^{\circ}$.

By careful integration of remote sensing and in-situ observations, and assimilation of these observations into hydrological and landslide/debris flow models with surface topographic information, prediction of useful probabilistic maps of landslide and floods for emergency management in a timely manner is possible. Early results shows that the potential exists for successful application of satellite precipitation data in improving/developing global monitoring systems for flood/landslide disaster preparedness and management. The scientific and technological prototype can be first applied in a representative test-bed and then the information deliverables for the region can be tailored to the societal and economic needs of the represented affected countries.

Acknowledgement: This research is carried out with support from NASA's Applied Sciences program under Steven Ambrose of NASA Headquarters. 


\title{
Flood and Landslide Applications of Near Real-time Satellite Rainfall Products
}

Yang Hong (1, 2), Robert F. Adler (2), Andrw Negri (2), George J. Huffman (2, 3)

\author{
${ }^{1}$ Goddard Earth and Science Technology Center/UMBC \\ ${ }^{2}$ NASA Goddard Space Flight Center, Laboratory for Atmospheres \\ ${ }^{4}$ Science Systems and Applications, Inc
}

Prepared for Joumal of Natural Hazards Special Issues:

Use of Satellite Remote Sensing for Natural Hazards Analysis

*Corresponding Author: Dr. Yang Hong

Mailing: NASA Goddard Space Flight Center, Mail code 613.1, Greenbelt, MD 20771

Phone: 1-301-614-6232; Fax: 1-301-614-5492; Email: 


\begin{abstract}
Floods and associated landslides account for the largest number of natural disasters and affect more people than any other type of natural disaster. With the availability of satellite rainfall analyses at fine time and space resolution, it has also become possible to mitigate such hazards on a near-global basis. In this article, a framework to detect floods and landslides related to heavy rain events in near-real-time is proposed. Key components of the framework are: a fine resolution precipitation acquisition system; a comprehensive land surface database; a hydrological modeling component; and landslide and debris flow model components. A key precipitation input dataset for the integrated applications is the NASA TRMM-based multisatellite precipitation estimates. This dataset provides near real-time precipitation at a spatialtemporal resolution of 3 hours and $0.25^{\circ} \times 0.25^{\circ}$. In combination with global land surface datasets it is now possible to expand regional hazard modeling components into a global identification/monitoring system for flood/landslide disaster preparedness and mitigation.
\end{abstract}

Keywords: Satellite Remote Sensing, Precipitation, Flood, Landslide 


\section{Introduction}

Floods and associated landslides are one of the most widespread natural hazards on Earth, responsible for tens of thousands of deaths and billions of dollars in property damage every year. During 1993-2002, over 1000 of the more than 2,900 natural disasters reported were due to floods (World Disaster Report, 2003). These floods and associated landslides claimed over 90,000 lives, affected over 1.4 billion people and cost about $\$ 210$ billion (US Dollars in 2002). The impact of these disasters is often felt most acutely in less developed regions (Hong et al., 2006a). In many countries around the world, satellite-based precipitation estimation may be the best source of rainfall data due to lack of surface observing networks (Adler et al., 2003; Hong et al., 2004). Naturally, this space-borne precipitation data is of potential useful for monitoring such hazards over such data sparse areas. An example monitoring display of the National Aeronautics and Space Administration (NASA) multisatellite rainfall product is shown in Figure 1. Tropical storm Xangsane, after forming just east of the central Philippines, intensified into a typhoon and battered the central Philippines with high winds and heavy rains on $27-28$ of September 2006. At least 110 people were reported killed with others missing as a result of flooding and mudslides brought on by the storm. After passing through the Philippines and traversing the South China Sea, Xangsane headed for the central coast of Vietnam where it made landfall on 1 October, causing widespread damage and flooding. At least 59 people were reported to have died there as a result. We believe that if people had been better informed and prepared, substantially fewer would have died. This is particularly true in countries with modest weather services (Negri et al., 2004a).

Satellite observations can be of value in improving the detection and warning of hazardous events and possibly in decreasing the mortality rate. 
Incorporation of a hydrological model and slope stability analysis into the near real-time satellite rainfall monitoring system will improve the lead-time of disseminating disaster warning at a cost-effective way (Mahdi, 2006). This article proposes a potential application of satellite-based system to detect floods and landslides related to heavy rain events in nearreal-time. As shown in Figure 2, the framework is based on an approach that integrates more than one of the traditional Earth science disciplines, and encourages complementary use of models and data from multiple satellites and sensors (Negri et al., 2004b). The major components of the framework are:

- A high time resolution real-time precipitation data acquisition system (gauge, radar, infrared, microwave satellites)

- A comprehensive geospatial database including topography, soil, land cover, etc.

- A hydrological modeling component for peak streamflow and flow duration

- Landslide and debris flow model components that incorporate geology and ambient conditions

The Key precipitation dataset for the integrated applications is the NASA-based multisatellite precipitation estimation (near real-time precipitation at a spatial-temporal resolution of 3 hours and $0.25^{\circ} \times 0.25^{\circ}$ ). This will be used in combination with the global coverage data sets of land surface characteristics (e.g., elevation, vegetation) with the goal of expanding local decision-support systems into a flood/landslide monitoring and forecasting system for disaster preparedness and mitigation.

\section{The new suite of satellite remote sensing datasets relevant to flood/landslide hazards}

\subsection{Precipitation observations from space}

A long history of development in the estimation of precipitation from space has culminated in sophisticated satellite instruments and techniques to combine information from multiple 
satellites to produce long-term products useful for climate monitoring (Adler et al., 2003). A fine time resolution analysis, such as the Tropical Rainfall Measuring Mission (TRMM) Multi-satellite Precipitation Analysis (TMPA; Huffman et al., 2006), can be used for this study. The TMPA global rainfall map is produced by using TRMM to calibrate, or adjust, the estimates from other satellite sensors, and then combining all the estimates into the TMPA final analysis. The coverage of the TMPA depends on combined coverage input from different sets of sensors. First, passive microwave data are collected by a variety of lowEarth-orbiting satellites, including the TRMM Microwave Imager (TMI) on TRMM, Special Sensor Microwave/Imager on Defense Meteorological Satellite Program (DMSP) satellites, Advanced Microwave Scanning Radiometer for the Earth Observing System (AMSR-E) on Aqua, and the Advanced Microwave Sounding Unit B (AMSU-B) on the National Oceanic and Atmospheric Administration (NOAA) satellite series. The second major data source for the TMPA is the window-channel ( 10.7 micron) infrared (IR) data that are being collected by the international constellation of geosynchronous-Earth-orbit satellites, which provide excellent time-space coverage (half-hourly, 4x4-km-equivalent lat./long. grids). This product is available from the Climate Prediction Center of the NOAA/National Weather Service (Janowiak et al, 2001). The IR brightness temperatures are corrected for zenith-angle viewing effects and inter-satellite calibration differences between these geosynchronous satellites. Finally, the research TMPA also makes use of three additional data sources: the TRMM Combined Instrument (TCI) estimate, which employs data from both TMI and the TRMM Precipitation Radar, as a source of calibration; the monthly rain gauge analysis developed by the Global Precipitation Climatology Centre (GPCC); and the Climate Assessment and Monitoring System monthly rain gauge analysis.

The TMPA is the standard product of TRMM, and is being computed for the entire TRMM period (January 1998-present) as product 3B-42 of the TRMM Version 6 processing 
currently underway. A real-time version (without the gage-adjustment and TCI) of the merged rainfall product was introduced since February 2002 and is available on the TRMM web site (trmm.gsfc.nasa.gov). Figure 3 (top) shows an example of an instantaneous rain rate map while Figure 3 (bottom) shows a seven-day accumulation map ending at the observed time. Also available are regional blow-ups and 7-day movie loops so that the evolution of the rain totals can be diagnosed.

\subsection{Datasets of land Surface Characteristics}

The basic digital elevation model (DEM) data sets considered in this system include NASA Shuttle Radar Topography Mission (SRTM; http://www2.jpl.nasa.gov/sttm/) and U.S. Geological Survey's GTOPO30 ((http://edcdaac.usgs.gov/gtopo30/gtopo30.html). The DEM data are used to derive topographic factors (slope, aspect, curvature, etc.) and hydrological parameters (flow direction, flow path, etc.). The global land cover data from MODIS (Moderate Resolution Imaging Spectroradiometer; http://modis.gsfc.nasa.gov/) are used as a surrogate for vegetation and land use types. The highest resolution of the MODIS land cover classification map is 250-meter. The MODIS land cover product describes the geographic distribution of the 17 IGBP land cover types based on an annual time series of observations. Global soil property data sets are taken from Digital Soil of the World published in 2003 by the Food and Agriculture Organization of the United Nations (http://www.fao.org/AG/agl/agll/dsmw.htm) and available in the International Satellite Land Surface Climatology Project Initiative II (ISLSCP II) Data Collection (http://www.gewex.org/islscp.html). The soil parameters used in this study are soil property information (including clay mineralogy and soil depth) and 12 soil texture classes, following the U.S. Department of Agriculture soil texture classification. Here we only list limited information, please refer to their websites for more detailed information. 


\section{Prediction of Floods and Landslide using Satellite Rain Products}

\subsection{Mapping Severe Flood Events}

The most effective means to reduce the property damage and life loss caused by floods is the use of warning systems. However, progress in global/regional flood monitoring and forecasting has been constrained by the difficulty in estimating rainfall continuously at catchment-scale to continental-scale, and even global-scale. Satellite-based precipitation estimation is of potential useful in this regard. For example, from the flow of TRMM-based, real-time precipitation information (Figure 3), simple flood-related maps can be produced and displayed on webpage and updated every three hours. Fig. 4a shows an example of the quasi-global "flood potential" maps that are produced in real-time (this example is from 8 Jan. 2005). Starting from global assessments such as Fig. 4a, users can zoom into regional images (Figure 4b) to diagnose the heavy rainfall/potential flood areas in much more detail. See for example, the floods in southern Japan on this date, or more recently, the flood potential map for southern Turkey on 1 Nov. 2006 (Fig. 4c). CNN later reported that the flash flood caused by torrential rain killed at least 21 people across southeast Turkey (http://www.cnn.com/2006/WORLD/europe/11/01/turkey.floods.reut/index.html). The early results demonstrate the potential of developing a satellite-based real-time flood detection system.

Satellite observations acquired and processed in real time can now provide the precipitation information needed to monitor severe flood events around the world by integrating satellitebased rainfall data with hydrological models. As shown in Figure 2, we put forward practical methods of mapping floods using a combination of data from TRMM-based precipitation and high resolution topography information and many other geospatial data sets, including soil properties and land cover information (Hong et al., 2006b). These data sets are used in 
conjunction with computationally efficient hydrological models to form the basis for the flood predictions. There have been several practices in line with this direction:

(a) In Asia, U.S. Foreign Disaster Assistance has engaged USGS and NOAA as partners in its Asia Flood Network activity, aimed at increasing the capacity of developing countries to forecast and mitigate floods. A key partner is the Mekong River Commission, which has a river-forecasting mandate on behalf of its member states: Cambodia, Laos, Thailand, and Vietnam. In 2003, NASA TMPA were added to the suite of daily downloads. These are ingested automatically into a geographic information system (GIS) system to calculate mean rainfall totals for subbasins of the Mekong, an invaluable supplement to unevenly distributed conventional gauge station data for operational river forecasting.

(b) A research group from Tennessee Technology University presented a relatively simple, modular watershed modeling approach for estimating the expected error in flood forecasting using input of satellite-based rainfall data and proposed its use to study many of the approximately 263 international river basins (IRB) listed by UNESCO (Katiyar and Hossain, 2006). This approach can be applied, therefore, even when conventional, realtime rainfall information from upstream nations is not available to the lower riparian nations due to a lack of in-situ rainfall measurement infrastructure or a lack of a treaty for real-time sharing of rainfall data. This approach is considered appropriate, despite some loss of detail and accuracy, in order to complete a global assessment of the large number of flood-prone IRBs.

(c) USGS experience with satellite rainfall estimates (RFE) began with the use of rainfall products as inputs to geospatial crop water balance modeling for agricultural drought monitoring over Sub-Saharan Africa. Using GIS technology, rainfall grids were first combined with digital maps of basins, land cover, soils, and evapotranspiration to produce Basin Excess Rainfall Maps (http:/edcintl.cr.usgs.gov/adds/), based on a 
USGS/NASA 30-arcsecond global topographic dataset, GTOPO30 (Gesch et al, 1999; Verdin and Verdin, 1999). USGS further used the Geospatial Stream Flow Model (GeoSFM) to simulate flow through the basin river network, using accepted hydrologic techniques in combination with channel routing methods (Artan et al., 2001). Thus, a hydrograph on a daily time interval is available for each catchment. These uncalibrated flow estimates are the basis of a color coded map of flood hazard that compares current discharge with a geomorphological bankfull flow value (http://www.sadc-hazards.net/). The GeoSFM is used operationally by USGS for monitoring in Southern Africa, and has been in use daily by the Mozambican water agency since 2002 to monitor the Limpopo River (Asante et al, 2004).

\subsection{Monitoring/forecasting Global Rainfall-triggered Landslides}

Useful assessment of landslide hazard requires an understanding of both where and under what conditions landslides may occur, which requires knowledge of the causative factors for landslides (Hong et al., 2006c). Dai et al. (2002) grouped these factors into two categories: (a) preparatory variables which make the land surface susceptible to failure (including topography, tectonics, geological history, weathering rates, land use, etc.) and (b) dynamic triggering factors (rainfall, earthquake, or glacier outburst). For this study, we are primarily concerned with shallow landslides that involve poorly consolidated soil or colluvium on steep hillslopes. Therefore, the first-order control on the spatial distribution of shallow landslides triggered by rainfall is the topographic slope of the ground surface, and first-order control on the temporal distribution of shallow landslides is the pore-pressure response in the soil or colluvium to infiltrating water (Iverson, 2000).

Evaluation of rainfall conditions that may trigger landsliding has typically relied on empirical correlations of combination of rainfall intensity and duration with landslide occurrence (e.g. 
Cain, 1980). Such relationships have been investigated for both tropical and mid-latitude regions. For example, landslide-triggering rainfall thresholds have been reported for Puerto Rico (Larsen and Simon, 1993), Hong Kong (Finlay et al, 1997), and central and southern California (Cannon, 1988). These empirical relations between rainfall intensity and rainstorm duration were regionally specific and often take the form of a power-law relation (Figure 5) and were applied once an the rainfall thresholds were reached.

Figure 2 outlines an experimental prediction system for rainfall-triggered landslide occurrence: (a) a global landslide susceptibility map was first derived using SRTM elevation, slopes, land cover, soil texture, and soil types (Hong et al., 2006d); and (b) this map is then overlain with the near real-time TRMM-based multi-satellite rainfall data to identify when landslide-prone areas receive heavy rainfall. The empirical rainfall intensity-duration (I-D) threshold is derived by examining rainfall characteristics which triggered landslides in a variety of locations around world (Fig. 6). The rainfall intensity-duration (I-D) threshold triggering landslides was approximated by inspection to the lower boundary of the scattered data (74 squares) and the expressions are:

$$
I=12.45 D^{-0.42} \text { for } 3 \text { hour }<=D<=240 \text { hours }
$$

In comparison, the satellite rainfall based threshold is approximately 0.75 of the algorithm from Caine 1980 and it is possibly due to the coarser spatial scale of the TRMM rainfall data against the gauge point measurement. Despite the variations, it is clear that the occurrences of landslides require intense rainfall, sustained for at least a brief period of time. These results, after regionalization, provide a possible basis to develop an early warning system for global rainfall-triggered landslides.

\section{Towards an Integrated Rainfall-triggered flood/landslide Analysis}


Unlike volcanoes and earthquakes, the flood and associated landslide hazards typically retum every year (Negri et al., 2004b). Satellite observations can be of essential value in improving our understanding of the occurrence of hazardous events and possibly in lessening their impact on local economies and in reducing injuries, if they can be used to create reliable warning systems in cost-effective ways. This article addressed these opportunities and challenges by describing a combination of satellite-based real-time precipitation estimation with land surface characteristics as input, with empirical and numerical models to map potential of landslides and floods. By careful integration of remote sensing and in-situ observations, and assimilation of these observations into hydrological and landslide/debris flow models with surface topographic information, prediction of useful probabilistic maps of landslide and floods for emergency management in a timely manner is possible (Negri et al., 2004b). Early results shows that the potential exists for successful application of satellite precipitation data in improving/developing global monitoring systems for flood/landslide disaster preparedness and management. The scientific and technological prototype can be first applied in a representative test-bed and then the information deliverables for the region can be tailored to the societal and economic needs of the represented affected countries.

Acknowledgement: This research is carried out with support from NASA's Applied Sciences program under Steven Ambrose of NASA Headquarters. 


\section{Reference}

Adler, R. F., Huffman, G J., Chang, A., Ferraro, R., Xie, P., Janowiak, J., Rudolf, B., Schneider, U., Curtis, S., Bolvin, D., Gruber, A., Susskind, J., Arkin, P., and Nelkin, E., 2003: The version-2 Global Precipitation Climatology Project (GPCP) monthly precipitation analysis (1979-Present), J. Hydrometeor., 4, 1147-1167.

Artan, G., J. Verdin, and K. Asante, 2001: A wide-area flood risk monitoring model. Fifth International Workshop on Application of Remote Sensing in Hydrology, Montpellier, France, October 2-5.

Asante, K. O., R. M. Dezanove, G. Artan, and J. Verdin, 2005: Developing a flood forecasting system from remotely sensed data for the Limpopo Basin. Journal of Spatial Hydrology, in review.

Caine, N., 1980: The rainfall intensity-duration control of shallow landslides and debris flows: Geografiska Annaler, v. 62A, p. 23-27.

Cannon, S.H., 1988: Regional rainfall-threshold conditions for abundant debris-flow activity, in Ellen, S.D., and Wieczorek, G.F., eds., Landslides, Floods, and Marine Effects of the Storm of January 3-5, 1982, in the San Francisco Bay Region, California: U.S. Geological Survey Professional Paper 1434, p. 35-42.

Dai, E.C., C.F. Lee, and Y.Y. Nagi, 2002: Landslide risk assessment and management: an overview, Engineering Geol., 64, 65-87.

Finlay, P.J., R. Fell, and P.K. Maguire, 1997: The relationship between the probability of landslide occurrence and rainfall: Canadian Geotechnical Journal, v. 34, p. 811-824.

Gesch, D.B., K. L. Verdin, and S. K. Greenlee, 1999: New land surface digital elevation model covers the Earth. EOS, Transactions of the American Geophysical Union, 80 (6): 69-70.

Hong, Y., K.L. Hsu, X. Gao, and S. Sorooshian, 2004, Precipitation Estimation from Remotely Sensed Imagery Using Artificial Neural Network - Cloud Classification System, Journal of Applied Meteorology, Vol. 43, No. 12, pp. 1834-1853

Hong, Y., R. Adler, and G. Huffman, 2006a: Evaluation of the NASA Multi-satellite Precipitation Analysis Potential in Global Landslide Hazard Assessment, Geophysical Research Letter (in press)

Hong, Y., R. Adler, G. Huffman, and A. Negri, 2006b, A Conceptual Framework for Spaceborne Flood Detection/Monitoring System, EOS Transaction, AGU, May 23-27, Baltimore, Maryland 
Hong, Yang, R.F. Adler, and G.J. Huffman, 2006c: An Experimental Global Monitoring System for Rainfall-triggered Landslides using Satellite Remote Sensing Information, IEEE Trans. on Geosciences and Remote Sensing (in press)

Hong, Y, R. Adler, G. Huffman, and A. Negri, 2006d: Use of Satellite Remote Sensing Data in mapping of global shallow landslides Susceptibility, Journal of Natural Hazards (accepted)

Huffman, G.J., R.F. Adler, D.T. Bolvin, G. Gu, E.J. Nelkin, K.P. Bowman, Y. Hong, E.F. Stocker, D.B. Wolff, 2006: The TRMM Multi-satellite Precipitation Analysis: QuasiGlobal, Multi-Year, Combined-Sensor Precipitation, Estimates at Fine Scale. J. Hydrometeor, (in press)

Iverson, R. M., 2000: Landslide triggering by rain infiltration: Water Resources Research, v. 36, p. 1897-1910.

Katiyar, Nitin and Faisal Hossain, 2006, An Open-Book Modular Watershed Modeling Framework for Rapid Prototyping of GPM-based Flood Forecasting in International River Basins, EOS Transaction, AGU, May 23-27, Baltimore, Maryland

Larsen, M. C., and A. Simon, 1993: A rainfall intensity-duration threshold for landslides in a humid-tropical environment, Puerto Rico: Geografiska Annaler, v. 75A, p. 13-23.

Mahdi, T., 2006, Pairing geotechnics and fluvial hydraulics for the prediction of the hazard zones of an exceptional flooding, Natural Hazards (to appear)

Negri, A, N. Burkardt, J. H. Golden, J. B. Halverson, G. J. Huffman, M. C. Larsen, J. A. Mcginley, R. G. Updike, J. P. Verdin, and G. F. Wieczorek, 2004a, The Hurricane-Flood-Landslide Continuum, BAMS, DOI:10.1175/BAMS-86-9-1241

Negri, A.J. Golden, J. H., and Updike, R. G., 2004, The Hurricane-Flood-Landslide Continuum -Forecasting Hurricane Effects at Landfall, American Meteorology Society Annual Conference, Miami, Florida, Jan., 2004b.

Verdin, K. and J. Verdin, 1999: A topological system for delineation and codification of the Earth's river basins. Journal of Hydrology 218: 1-12.

World Disasters Report, 2003, International Federation of Red Cross and Red Crescent Societies (IFRCRCS).Preparedness for climate change, a study to assess the future impact of climatic changes upon the frequency and severity of disasters and the implications for humanitarian response and preparedness.Geneva:IFRCRCS.P239 


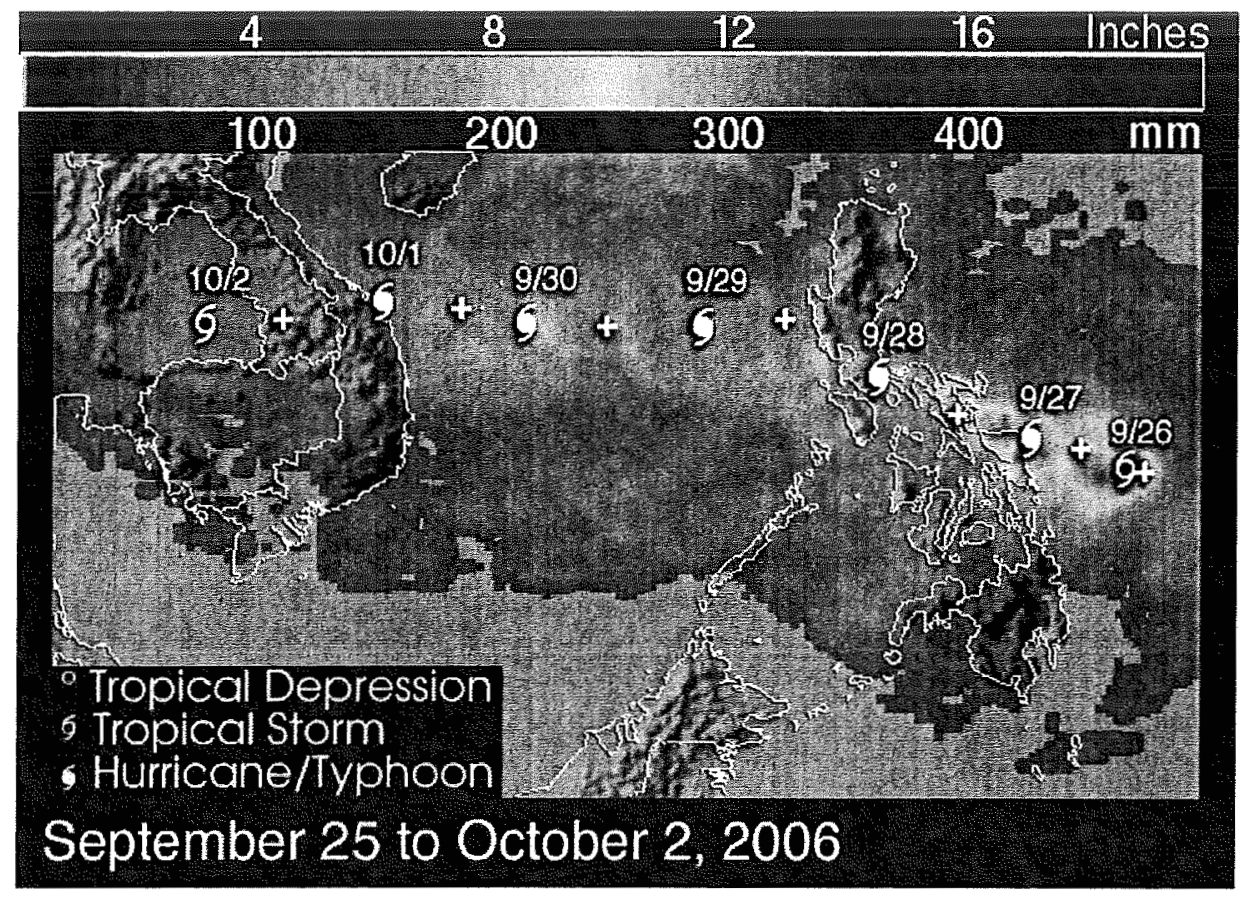

Figure 1. Tropical storm Xangsane caused floods and landslides to Philippines and Vietnam. At least 169 people were reported killed with many missing as a result of flooding and mudslides brought on by the storm. Storm symbols mark Xangsane's path. Rainfall totals of over $300 \mathrm{~mm}$ are shown over Samar in the east central Philippines (red areas). A broad area of 100-200 mm totals (green) stretch from the central Philippines to the coast of Vietnam. 


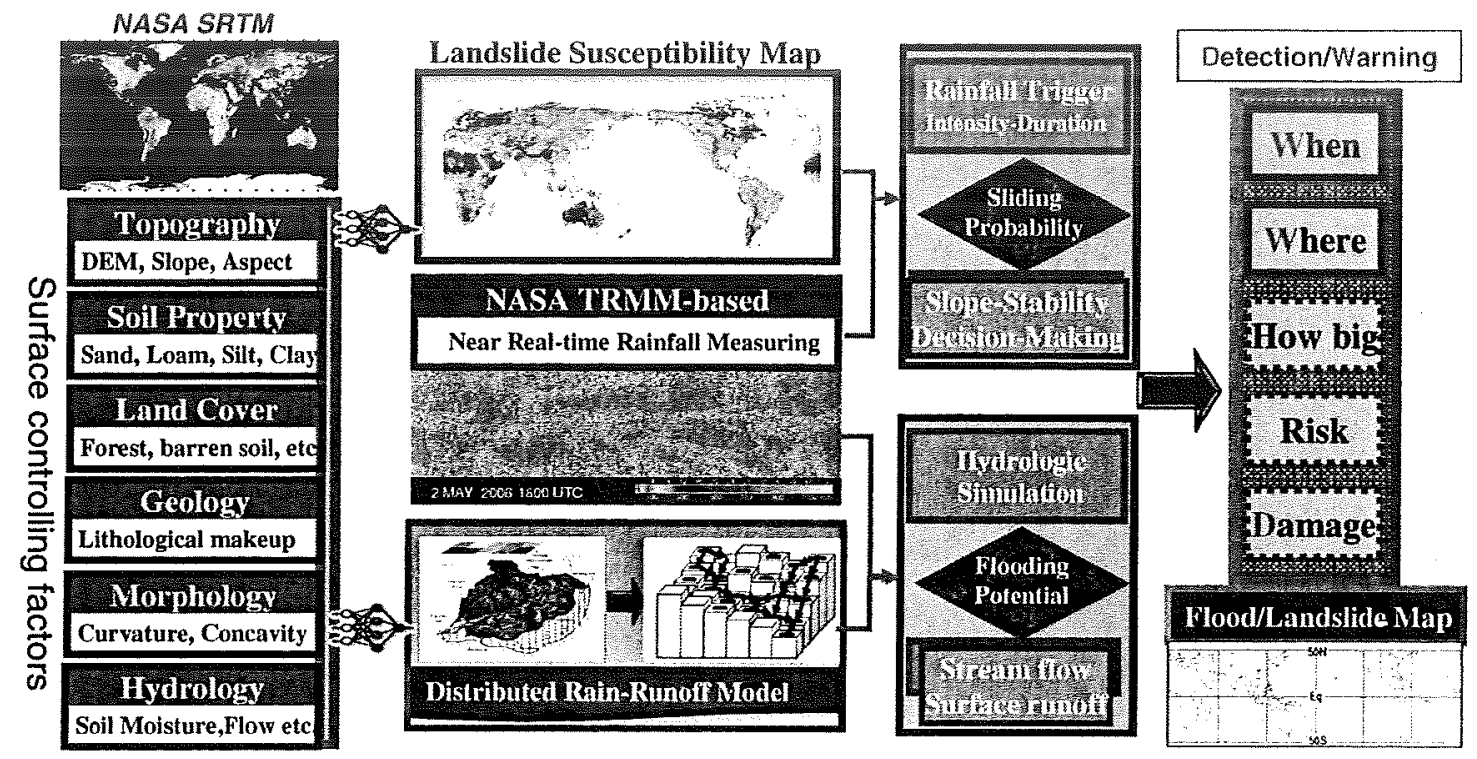

Figure 2. The conceptual framework for monitoring rainfall-triggered flood/landslides at global scale 


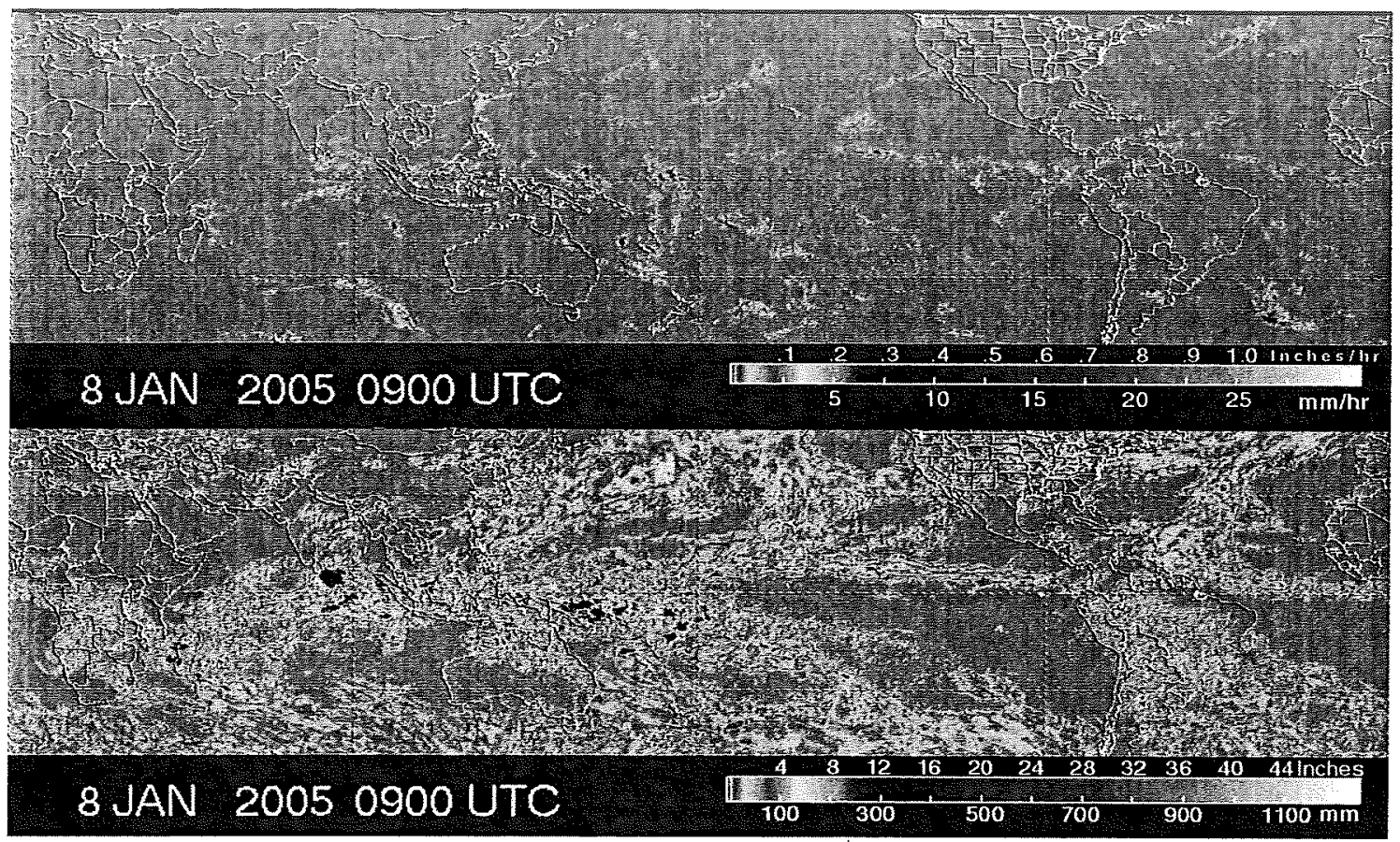

Figure 3. Example of NASA TRMM MPA instantaneous rain rate map (top panel) and seven day accumulation (bottom panel). 
(a)

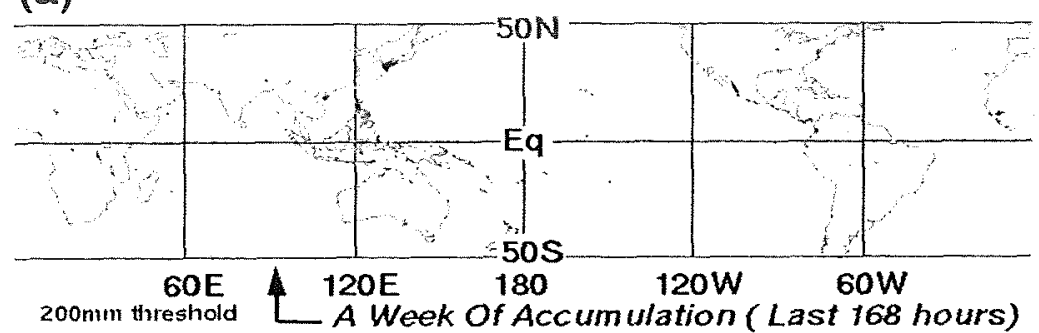

(b)

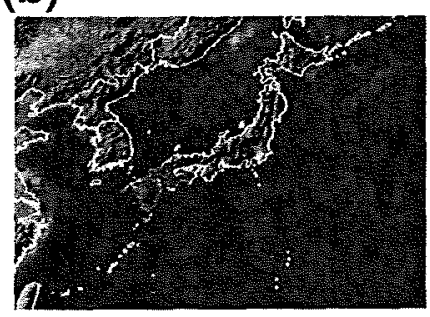

(c)

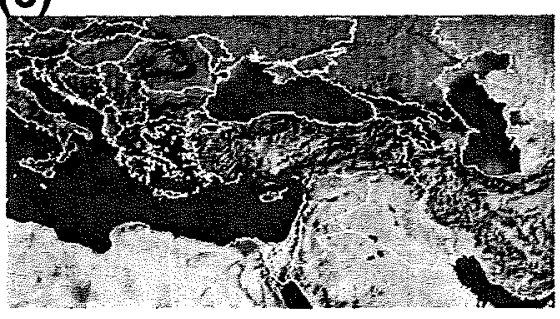

Figure 4. NASA TRMM-based flood potential maps: (a) the flood potential derived from figure 3; (b) the flooding in Japan on date of Jan. 8, 2005; and (c) flooding in Southern Turkey on date of Nov. 1, 2006 and verified by CNN news (http://www.cnn.com/2006/WORLD/europe/11/01/turkey.floods.reut/index.html). 


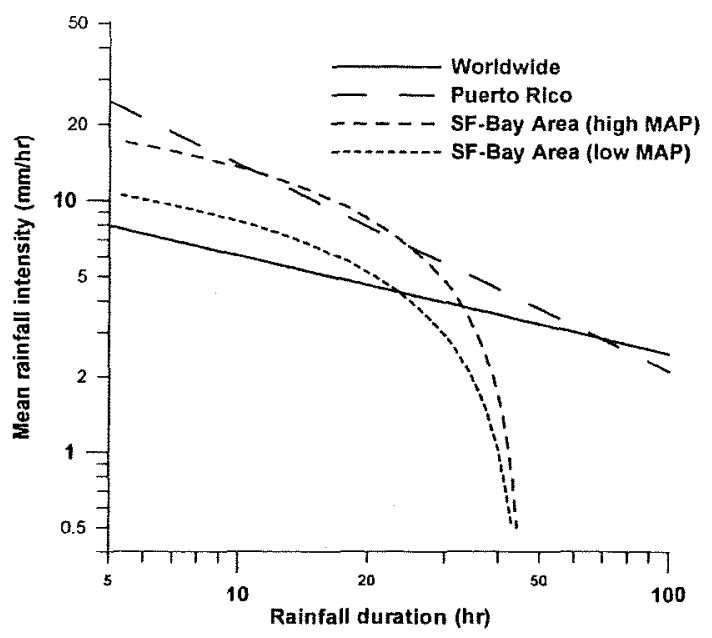

Figure 5. Comparison of threshold rainfall intensity and duration for the Puerto Rico (Larsen and Simon, 1993), San Francisco Bay Area (Cannon, 1988), and worldwide (Caine, 1980) data sets. The two threshold curves shown for the San Francisco Bay Area are normalized based on mean annual precipitation 

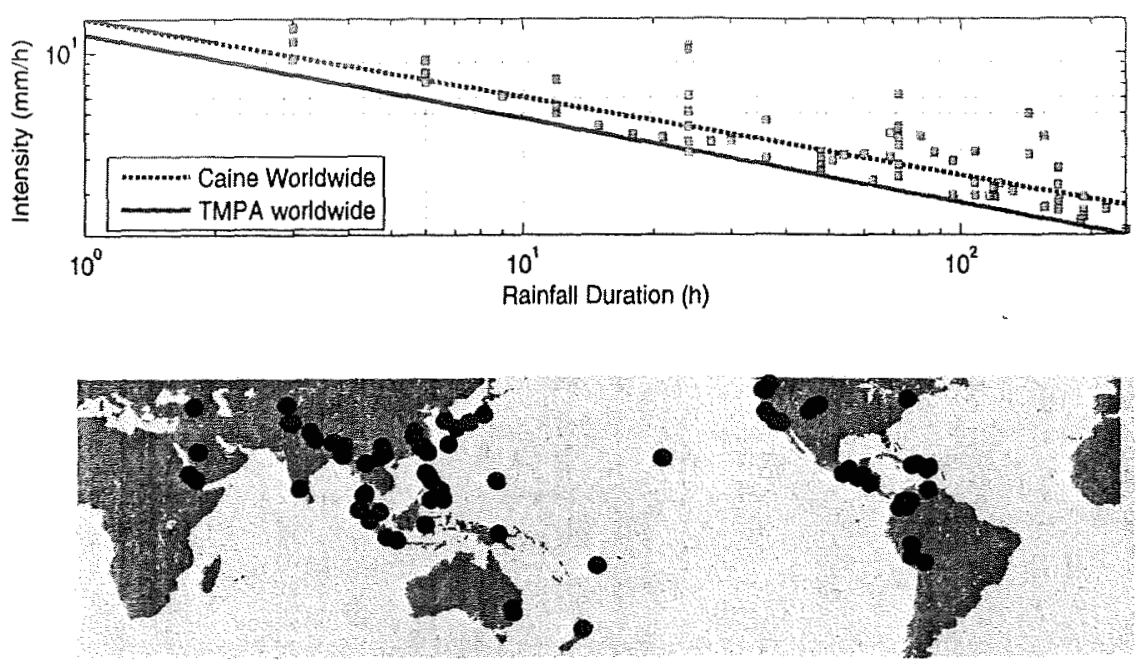

Figure 6. (a) The locations of the landslide occurrences and (b) the lower bound of rainfall intensity-duration threshold (dash line: Intensity $=12.45$ Duration-0.42) for landslides (squares) that occurred in (a) is approximately 0.75 of the global algorithm from Caine 1980 (dark dash line). 